\title{
Laboratory study of the migration of methane sulphonate in firn
}

\author{
Elizabeth C. Pasteur, Robert Mulvaney \\ British Antartic Survey, Natural Environment Research Council, High Cross, Cambridge CB3 OET, England
}

\begin{abstract}
ABSTR ACT. Two $10 \mathrm{~cm}$ lengths of firn core from the Dyer Plateau $\left(70^{\circ} 31^{\prime} \mathrm{S}, 65^{\circ} 01^{\prime} \mathrm{W}\right)$, Antarctic Peninsula, were used to carry out a laboratory experiment to investigate the migration of methane sulphonate, the anion of methane sulphonic acid (MSA), in natural firn. Each length was cut vertically into four pieces, and a dopant solution containing $\mathrm{Cl}^{-}$, $\mathrm{NO}_{3}{ }^{-}, \mathrm{SO}_{4}{ }^{2-}, \mathrm{F}^{-}$and $\mathrm{MSA}^{-}$pipetted onto the top of three sections, the fourth being kept as a blank. The doped sections were stored vertically, with the doped end uppermost, for 8 months at a range of temperatures (nominally $-5^{\circ},-10^{\circ}$ and $-22^{\circ} \mathrm{C}$ ) before subsampling at $1 \mathrm{~cm}$ resolution and analysis by ion chromatography. The two firn lengths were treatcd identically and the results were consistent. Profiles of the doped firn scctions showed that $\mathrm{Cl}^{-}, \mathrm{NO}_{3}$ and $\mathrm{SO}_{4}{ }^{2-}$ remained in the uppermost subsample, although the $\mathrm{NO}_{3}{ }^{-}$concentrations were variable compared to the blank. The $\mathrm{F}$ profile shows slightly elevated concentrations in the second sample down compared to the blank, at temperatures of $-10^{\circ} \mathrm{C}$ and above. The $\mathrm{MSA}^{-}$showed higher concentrations in the second, third and fourth samples down at $-10^{\circ} \mathrm{C}$ and above, which indicates that some percolated downwards from its original position at the top of the core. This cxperiment shows that MSA is mobile in warm firn even over a short period of time. We propose that the mechanism for the mobility of $\mathrm{MSA}^{-}$in natural firn is via liquid MSA drainage, though we cannot yet discount vapour phase transport.
\end{abstract}

\section{INTRODUCTION}

Emissions of dimethyl sulphide (DMS) in the remote marine atmosphere represent a major natural source of sulphur, both in the remote atmosphere and on a global scale (Spiro and others, 1992). DMS is the only atmospheric source of methane sulphonate ( $\mathrm{MSA}^{-}$), and measurements of MSA in the atmosphere and in icc corcs offer a potential indicator of marine biogenic activity in the present and past. (MSA is gencrally assumed to be transported and deposited in its acidic form, methane sulphonic acid (MS $\Lambda$ ), but is generally measured by ion chromatography as the anion $\mathrm{MSA}^{-}$. Non-sea-salt sulphate ( $\mathrm{nssSO}_{4}{ }^{2}$ ) is also produced by DMS in the atmosphere, and several studies have measured MSA and $\mathrm{nssO}_{1}{ }^{2}$ in aerosol, surface snow, firn and ice cores to evaluate short- and long-term changes in marine cmissions of DMS (Legrand and others, 1991; Pasteur and others, 1995; Wagenbach, 1996).

In the reconstruction of past atmospheric composition from ice cores, the assumption is often made that there is no post-depositional modification of the chemistry during diagenesis of the firn. However, it has been reported that MSA shows post-depositional relocation in some Antarctic firn and ice cores (Mulvaney and others, 1992; Minikin and othcrs, 1994; Pastcur, 1996). Aerosol and surfacc-snow measurements confirm that $\mathrm{MSA}^{-}$reaches a maximum in summer, and is at a minimum in winter (Savoic and others, 1993; Wagenbach, 1996), consistent with the predominantly summertimc production of DMS. A similar summer/winter contrast in $\mathrm{MS}^{-}$is also seen in the first few layers of snow deposition. Deeper in the firn, however, $\mathrm{MSA}^{-}$can become concentrated in the winter layer, defincd by $\mathrm{nssSO}_{4}{ }^{2}$ and oxygen isotope $\left(\delta^{18} \mathrm{O}\right)$ ratios reaching their winter minimum values. This apparent change in the seasonality of $\mathrm{MSA}^{-}$is demonstrated in an ice-core profile from Berkner Island ( $78^{\circ} 18^{\prime} \mathrm{S}, 46^{\circ} 17^{\prime} \mathrm{W}$ ), situated on the Filchner Ronne Ice Shelf, Antarctica (Fig. 1). In the shallower section the $\mathrm{MSA}^{-}$concentrations are highest during the summer and in phasc with $\mathrm{nssSO}_{4}{ }^{2}$ and $\delta^{18} \mathrm{O}$, whilst in the decper core section the $\mathrm{MSA}^{-}$concentrations are highest during the winter period, as shown by $\mathrm{nss}_{\mathrm{SO}}{ }^{2}$ winter minima. The change in the location of $\mathrm{MSA}^{-}$from the summer layer to the winter layer occurs at varying depths and times before drilling in ice cores from various locations in the Antarctic.

In the study reported here, the aim is to investigate the phenomenon of the change in seasonal location of $\mathrm{MSA}^{-}$in Antarctic corcs, by trying to mimic the conditions under which the change takes place under controlled conditions.

\section{EXPERIMENTAL}

The firn-core sections used for this experiment werc from the Dyer Plateau $\left(70^{\circ} 31^{\prime} \mathrm{S}, 65^{\circ} 01^{\prime} \mathrm{W}\right.$ ) on the Antarctic Peninsula, from a depth of $10 \mathrm{~m}$ from the surfacc. This section was chosen because the Dyer Plateau has relatively low $\mathrm{MSA}^{-}$ conccntrations (average $8 \mu \mathrm{gL}^{\text {l) }}$ ) and there would therefore be little interference from background levels.

Two $10 \mathrm{~cm}$ lengths of core were taken and the outer surfaces removed with a clean scalpel. Both lengths were then cut vertically into four sections with a band-saw (Fig. 2). Each section wcighed approximately $100 \mathrm{~g}$. One section from each core length was used as a blank and was sealcd in pre-clcaned layflat tubing and stood vertically in an insu- 

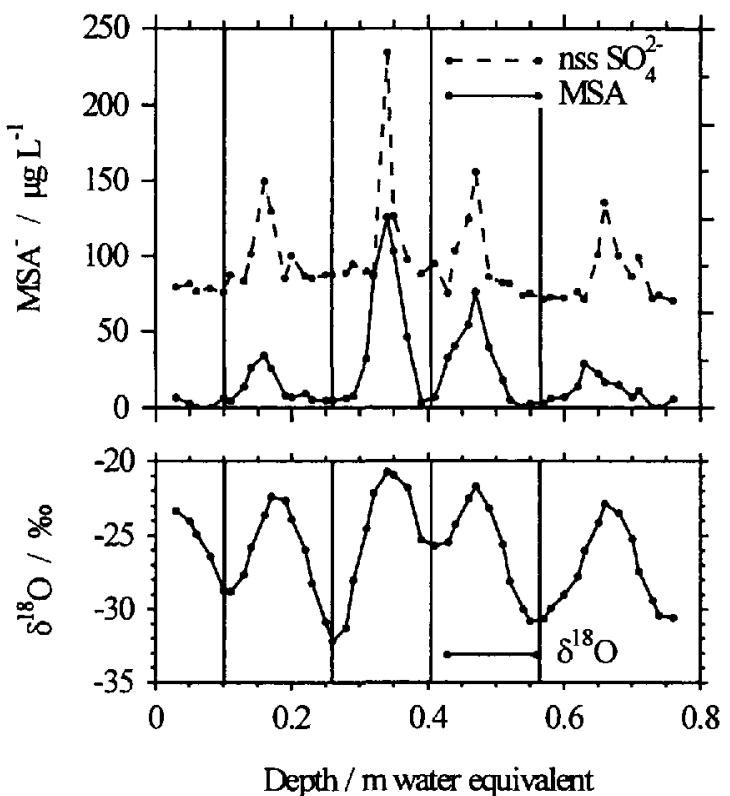

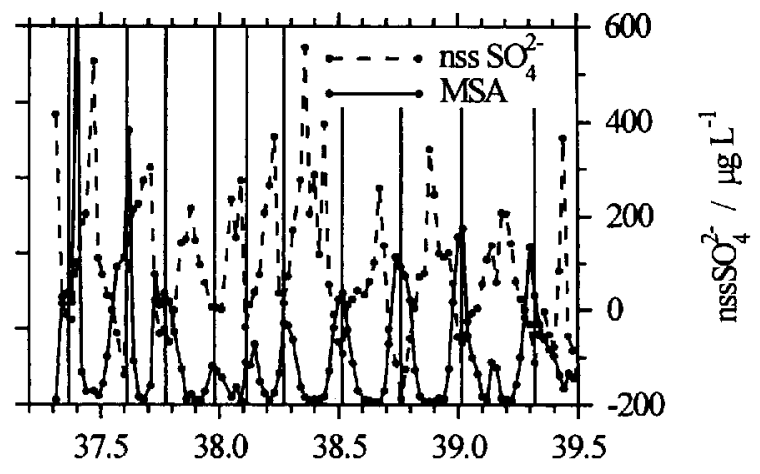

Fig. 1. Anion profiles from near the surface and at depth in ice cores collected from Berkner Island $\left(78^{\circ} 18^{\circ} \mathrm{S}, 46^{\circ} 17^{\circ} \mathrm{W}\right)$. The nearsurface MSA and nss $S O{ }_{1}{ }^{2-}$ have maxima in the summer, when the oxygen isotope signal, $\delta^{18} O$, is also at a maximum. Deeper in the core, $\mathrm{MSA}$ and nss $\mathrm{SO}_{4}{ }^{2-}$ are out of phase, with MSA reaching a maximum in the winter layer. Isotope data are not available for this section.

lated Perspex core holder. $0.5 \mathrm{~mL}$, of solution containing the sodium salt of $\mathrm{MSA}^{-}\left(10 \mathrm{mg} \mathrm{L}{ }^{-1}\right)$ and potassium salts of $F$ $\left(10 \mathrm{mg} \mathrm{L}^{-1}\right), \mathrm{NO}_{3}{ }^{-}\left(10 \mathrm{mg} \mathrm{L}^{-1}\right), \mathrm{Cl} \quad\left(60 \mathrm{mg} \mathrm{L}^{\mathrm{l}}\right)$ and $\mathrm{SO}_{4}{ }^{2-}$ $(60 \mathrm{mg} \mathrm{L}$ ) was pipetted onto the top of the three remaining core sections. This volume and concentration were chosen to give an approximate mean concentration similar to that seen in coastal ice cores, of $300 \mu \mathrm{g} \mathrm{L}^{-1} \mathrm{Cl}^{-}$and $\mathrm{SO}_{4}{ }^{2-}$ and $50 \mu \mathrm{g} \mathrm{L}^{-1}$ each of $\mathrm{F}^{-}, \mathrm{NO}_{3}$ and $\mathrm{MSA}^{-}$, if mixed with the full $100 \mathrm{~g}$ of liquid in each section: this is used latcr to test the conscrvation of the ions after storage (Table 2). The solution was added dropwise over the full cross-section (apart from the outer $2 \mathrm{~mm}$ ) to minimise immediate percolation. Fach of the two firn-core lengths was treatcd in the samc manncr. These sections were then sealed in polyethylene tubing and stored vertically and in the same orientation as the blanks. The firn sections were labelled $l a-d$ and $2 a-d$, where la and $2 \mathrm{a}$ were blanks and $1 \mathrm{~b}-\mathrm{d}$ and $2 \mathrm{~b}-\mathrm{d}$ were the doped samples.

The ice-core sections were stored for 8 months at a range of temperatures, which were recorded using an electronic temperature logger. The blank ( $1 \mathrm{a}$ and 2a) and one of the doped sections ( $1 \mathrm{~b}$ and $2 \mathrm{~b}$ ) werc stored in a cold room at nominally $-22^{\circ} \mathrm{C}$ (actual range $-25^{\circ}$ to $-20^{\circ} \mathrm{C}$ ). Figure 3 shows the temperat ure variations over a 1 day period, and for this cold room the two spikes in temperature represent defrost cycles for the freezer unit. Samples 1c and 2c were

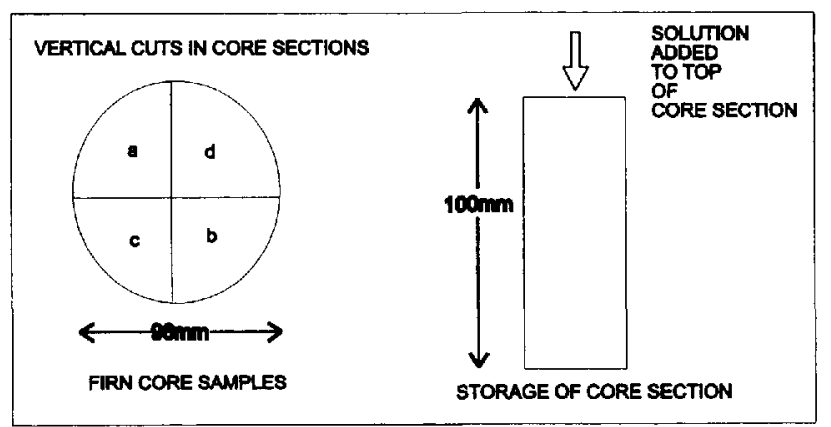

Fig. 2. Method of cutting and doping the samples.

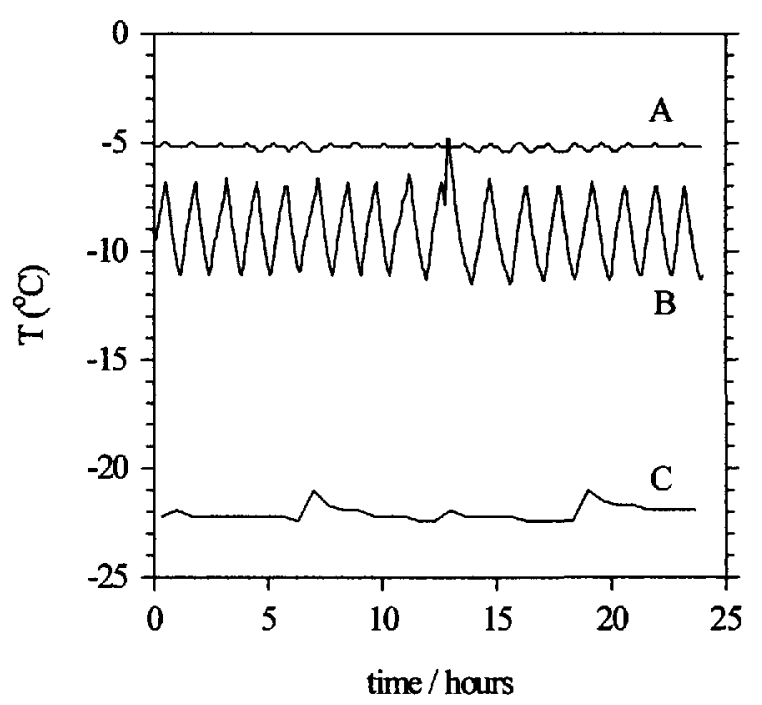

Fig. 3. Typical temperature regimes experienced by the firn sections during the 8 month storage period. $A:-5^{\circ} \mathrm{C}$ chest freezer, measured at 10 min intervals (samples $1 d$ and $2 d$ ); $B:-10^{\circ} \mathrm{C}$ cold room, measured at 5 min intervals (samples $1 c$ and $2 c$ ); C: $-22^{\circ} \mathrm{C}$ cold room, measured at 40 min interials (samples $1 a, 1 b, 2 a$ and $2 b)$.

stored in a cold room at nominally $-10^{\circ} \mathrm{C}$. The fluctuation in tempcrature in this cold room is quite high, with variations from $-11^{\circ}$ to $5^{\circ} \mathrm{C}$ (Fig. 3). Samples ld and $2 \mathrm{~d}$ were stored in a chest freczer at $-5^{\circ} \mathrm{C}$; the temperature in this freezer was relatively constant (Fig. 3). For a period of 10 weeks during the 8 months, this freczer was required for other purposes, and the samples were then stored at $-22^{\circ} \mathrm{C}$.

At the end of the 8 month storage period, the core sections were cut into $1 \mathrm{~cm}$ samples, with cuts made parallel to the upper doped surface, and melted for analysis. Analyses were carried out on a Dionex ion chromatograph, using AG11/ASll columns, a degassed hydroxide eluent and a gradient pump, using a $500 \mu \mathrm{L}$ sample volume. During all cutting, doping, subsampling and analytical work, full cleanroom clothing including face mask and polythene gloves 
were worn to avoid any contamination of the samples. The melting containers were all pre-cleaned several times with $18 \mathrm{M} \Omega \mathrm{cm}$ water.

\section{RESULTS}

Table I shows the blank concent rations measured for several pure water samples and a procedural blank from an artificial ice core made from frozen pure water which was processed in the same way as the samples. The concentrations

Table 1. Blanks showing anion concentrations ( $\mu \mathrm{g} L^{-1}$ (std. der, $\sigma)$ ) attributable to sample handling and analysis

\begin{tabular}{lccccc}
\hline Blank & $F$ & $\mathrm{MSA}$ & $\mathrm{Cl}$ & $\mathrm{NO}_{3}$ & $\mathrm{SO}_{4}{ }^{2}$ \\
\hline Average water & $0.6(0.93)$ & $0(0)$ & $4.5(2.4)$ & $12.0(14.0)$ & $10.3(3.2)$ \\
Procedural blank & 2.9 & 0 & 99 & 25.5 & 16.3 \\
\hline
\end{tabular}

Bite: The procedural blank was obtained by preparing an ice core from frozen $18 \mathrm{M} \Omega \mathrm{cm}$ water which was then cut, melted and transferred into a sample vial for analysis in the same way as the firn-core sections.

for nitrate were high and variable, so these data are not presented here. In Table 2, we calculate a full budget of the analytical results from each sample and we note that we can account for the full amount of introduced dopant; none was lost from the stored ice sections.

Table 2. Overall budget of anions $\left(\mu g L^{I}\right)$ calculated by summing the concentrations for ach subsample

\begin{tabular}{|c|c|c|c|c|}
\hline Section & $F^{-}$ & $M S_{A} 1$ & Ct & $S O_{1}{ }^{2-}$ \\
\hline la blank & 2.5 & 4.4 & 32.5 & 39.8 \\
\hline lb & 54.9 & 5.2 .2 & 347.1 & 346.4 \\
\hline lc & 57.1 & 56.0 & 373.1 & 346.4 \\
\hline ld & 51.1 & 51.4 & 336.8 & 340.1 \\
\hline Mean b,c,d & 54.4 & 54.2 & 352.3 & 354.5 \\
\hline 2a (blank) & 1.9 & 4.0 & 47.9 & 41.8 \\
\hline $2 b$ & 50.4 & 50.7 & 313.6 & 312.8 \\
\hline $2 c$ & 62.7 & 62.1 & 411.1 & 427.8 \\
\hline $2 \mathrm{~d}$ & 50.5 & 48.0 & 3266 & 333.3 \\
\hline Mcan b,c,d & 54.5 & 53.7 & 350.4 & 358.0 \\
\hline
\end{tabular}

Sutes: The initial aliquot of dopant pipetted onto each section of ice should have resulted in mean concentrations, taken over the full section, of $300 \mu \mathrm{g} \mathrm{L}^{1} \mathrm{Cl}$ and $\mathrm{SO}_{4}{ }^{2}$, and $50 \mu \mathrm{g} \mathrm{L}^{-1}$ each of $\mathrm{F}^{-}, \mathrm{NO}_{3}{ }^{-}$and $\mathrm{MSA}^{-}$. Values lower than this would imply that the anion was lost from the core section; there is no evidence of loss, all the introduced amount being accounted for. Values higher than the expected mean are largely due to the blank ?i.e. the natural level in the original ice samples?

The results of the two series of doped and blank firn samples are shown in Figure 4: the results for series 1 and 2 are almost identical. If the dopant remained confined to the uppermost sample, we would expect concentrations of $3000 \mu \mathrm{g} \mathrm{L}^{-1}$ for $\mathrm{Cl}^{-}$and $\mathrm{SO}_{4}{ }^{2}$, and $500 \mu \mathrm{g} \mathrm{L}^{-1}$ for $\mathrm{F}^{-}$and $\mathrm{MSA}^{-}$in this sample. In all three doped sections, $\mathrm{Cl}^{-}$and $\mathrm{SO}_{4}{ }^{2-}$ have high concentrations in the top sample (similar to the value expected if the dopant remained in this sample) and then concentrations drop to background levels in second and subsequent samples. Wc conclude that none of the added anion solution percolated more than $1 \mathrm{~cm}$ though the core sample at any of the storage temperatures. $\mathrm{F}$ shows a high concentration in the top sample, and a concentration above the level of the blank in the sccond sample for the sections stored at $10^{\circ}$ and $5^{\circ} \mathrm{C}$. The third sample, which is $20-30 \mathrm{~mm}$ from the top, shows the doped samples at the same concentrations as the blank, and therefore represents the lower limit of percolation through the core section.

The result for $\mathrm{MSA}^{-}$shows a greater change: the top four samples all have concentrations higher than the blank at $-5^{\circ}$ and $-10^{\circ} \mathrm{C}$. This shows that some of the MSA added to the top of the core section has migrated up to $40 \mathrm{~mm}$ over the 8 month period. This is an important result: it confirms that a winter maximum in $\mathrm{MSA}^{-}$could be due to the migration of $\mathrm{MSA}^{-}$in firn from the summer to winter layers and not due to deposition of $\mathrm{MSA}^{-}$during winter months. Even at cold polar sites, summer temperatures in the upper few metres of the snowpack can be as warm as $-5^{\circ} \mathrm{C}$, making this result generally relevant.

\section{DISGUSSION}

The most significant feature of the data shown in Figure 4 is the obvious change in the MSA ${ }^{-}$signal below the doped surfacc. This change does not occur in the sample which was stored in the $-22 \mathrm{C}$ cold room (section b), but does occur in the core sections stored at $-10^{\circ} \mathrm{C}$ (c) and $-5^{\circ} \mathrm{C}$ (d). Tempcrature thercfore clearly has some influcnce over the movement of MSA. The MSA in core section $c$ appears to show a slightly greater degree of relocation than $\mathrm{d}$ which was stored at a warmer temperature with occasional periods at $-22^{\circ} \mathrm{C}$, but we can draw no conclusion from this. Despite no observation of $\mathrm{MSA}^{-}$migration in the samples stored at $-22^{\circ} \mathrm{C}$, it is clear from the Berkner Island data that migration can occur at a sitc where the tempcrature measured at $10 \mathrm{~m}$ (approximating to the mean annual air temperature) is about $-24^{\circ} \mathrm{C}$. At this site, migration is observed in the upper $10 \mathrm{~m}$ where summer temperatures are higher than the mean annual temperature, but is observed to continue below $10 \mathrm{~m}$ where the ice remains colder than $-22^{\circ} \mathrm{C}$. Presumably, the time-scale for migration is longer at lower tempcratures.

We can speculate on the migration process. During snowfall, impurities can be incorporated by nucleation scavenging, where acrosol particles act as condensation nuclei, or by within-cloud and below-cloud scavenging where particles and gases collect on the growing snowflake. Fresh snowfall can therefore hold impurities both within the ice structure and on the surface. During burial, however, recrystallisation forces some impurities to the boundaries of the growing snow grains. In a study of natural ice in an analytical scanning electron microscope, Mulvancy and others (1988) showed that in an Antarctic ice sample sulphuric acid was located at the boundaries of grains. They concluded that this acid must be liquid at ice-shect temperatures since sulphuric acid remains liquid as the composition follows the freezing-point curve of sulphuric-acid/water mixtures. At decreasing temperatures, water is lost from the mixture until it finally freezes at the eutectic temperature of $-73^{\circ} \mathrm{C}$. MSA (the form in which $\mathrm{MSA}^{-}$is deposited on the ice sheet) is a similar strong acid, with a similar freezing curve in dilute solutions (rcproduced in Fig. 5 ), and a eutectic temperature of below $-70^{\circ} \mathrm{C}$. We propose that MSA is also located as a dilute liquid at the grain boundaries in the ice sheet.

One possible migration mechanism may be by drainage of the liquid, depending on the temperature. As can be seen 
Series 1
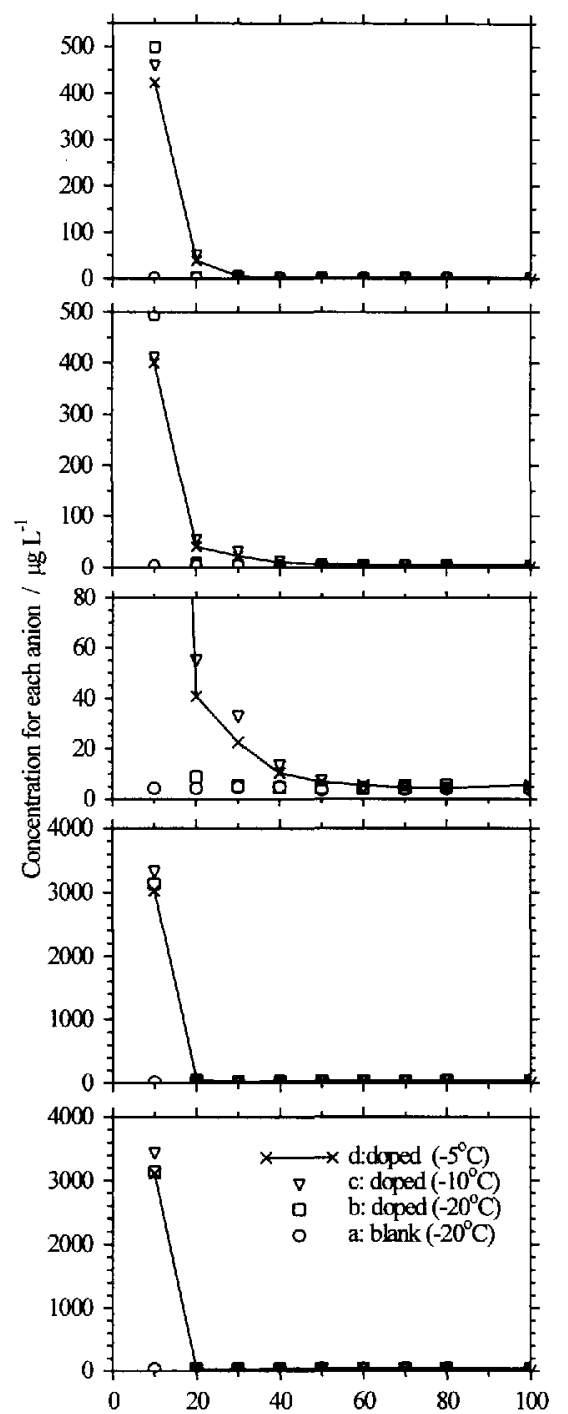

Series 2
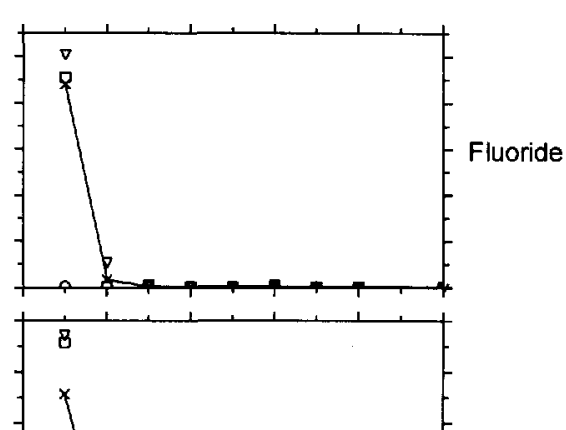

MSA

MSA
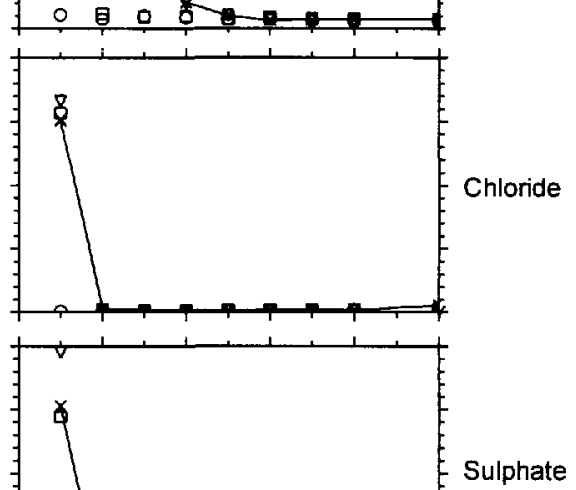

Lower limit of sub-sample from care section / mm

Fig. 4. Blank corrected anion profiles along the two series of doped firn sections: symbols for all panels are defined at lower left; connecting lines through symbols are omitted for clarity from all except sections $d$; subsample $0-10 \mathrm{~mm}$ plotted at $10 \mathrm{~mm}$ on the abscissa, etc. For $\mathrm{Cl}$ and $\mathrm{SO}_{f}{ }^{2}$ the added solution remains in the top $10 \mathrm{~mm}$ sample. For $F$ there is higher concentration in the second sample $(10-20 \mathrm{~mm})$ as well as the top sample. However, the most pronounced change is in the MSA profile of the section. stored at $10^{\circ}$ and $5^{\circ} \mathrm{C}$ (shown here al two scales for clarity), with higher than background MSA in the top four samples.

from the frcezing-point curve, as the mixture cools, water is frozen out of the mixture, leaving a decreasing volume of increasingly concentrated MSA. The limit at which the MSA migrates at a given temperature must depend on the grain-size and firn porosity, with capillary action acting against drainage of the liquid. For the same grain structure, at warmer temperatures, ice melts into the acid liquid to follow the freezing curve until a point is reached when drainage overcomes the capillary support, and migration of the MSA takes place. (This is similar to the springtime acidflush cvent observed in temperate snowpacks.) An alternative temperature-dependent mechanism that wc cannot discount from our experiment would be transport of MSA through the vapour phase, with the rate dependent on the vapour pressure at the experimental (or, by implication, the ice-sheel) temperature. However, if vapour transport were involved, then we might have expected to lose some MSA completely from the porous firn. Table 2 shows that this did not occur, with all the introduced dopant conserved in the final cut samples after storage.

While drainage could explain the migration of $\mathrm{MSA}^{-}$

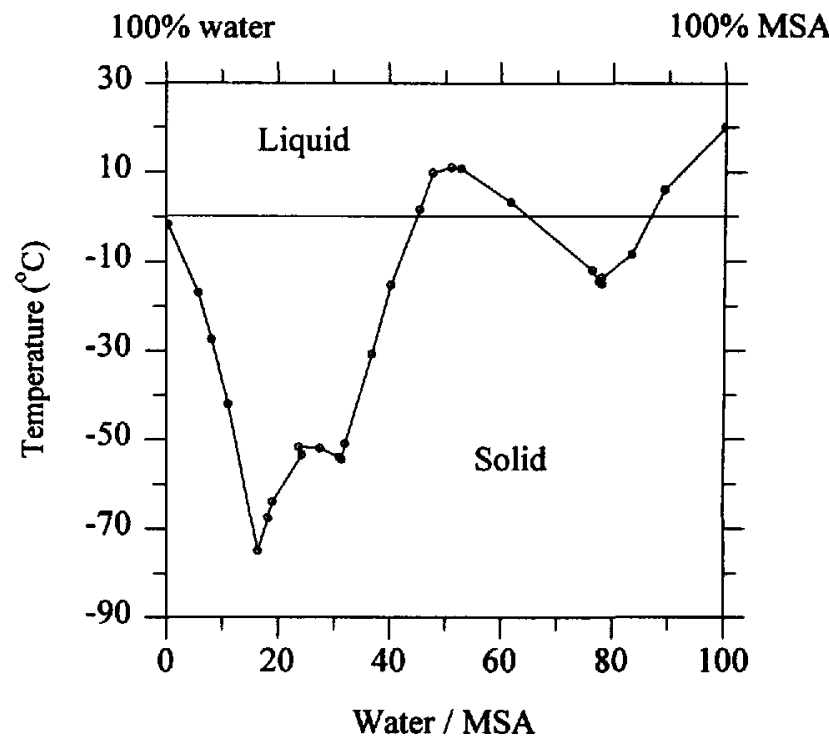

Fig. 5. Freezing curve for MSA/water mixtures. Data from Slephen and Stephen (1963,p. 374). 
within icc, it does not explain why $\mathrm{MSA}^{-}$preferentially migrates to the winter layer in natural ice, implying that the migration is not driven by a concentration gradicnt. This is likely to reflect an interaction of the $\mathrm{MSA}^{-}$ion with cations in the ice that are already located in the winter layer. Howcver, we have not defined the candidatc cation in our icccore data from sites where migration to the winter layer is clear.

Some questions remain to be answered. In our experiment, we used a sodium salt of MSA - is this a good analogue for natural Antarctic ice? We plan similar experiments with the pure acid. Why does MSA migrate in ice corcs, but apparently not sulphuric acid? Presumably this is due to the detailed physical chemistry of the two species and their interaction with ice. Finally, what limits the movement of $\mathrm{MSA}^{--}$to the winter layer as observed in natural ice cores?

\section{CONCLUSIONS}

In this simple cxperiment, it has been demonstrated that MSA moves within firn even after a period of only 8 months at temperatures of $-10^{\circ} \mathrm{C}$ and above. 'This confirms that the winter $\mathrm{MSA}^{-}$peaks which have been recorded in some ice cores could be due to migration of MSA in firn. The mechanism for this process appears temperature-dependent, and we suggest a mechanism based on the drainage of liquid MSA through the firn, but cannot discount the possibility that vapour transport is involved.

This experiment is continuing. At the same time as the two sequences of doped samples and blanks described here were prepared, four further sequences were prepared in an identical manner. It is hoped that doped core samples will be measured each year for 4 years so that the final core sections analyzed will have been in storage for 5 years after doping) to see if the $\mathrm{MSA}^{-}$migration continucs in a linear way and to see if any migration occurs at $-20^{\circ} \mathrm{C}$ over longer time periods. We also plan further experiments to differentiate between diffusion and drainage.

\section{REFERENCES}

I,egrand, M., C. Feniet-Saigne, E. S. Saltzman, C. Germain, N. I. Barkov and V. N. Petrov. 1991. Ice-core record of oceanic emissions of dimethylsulphide during the last climate cycle. Nature, $350(6314), 144-146$.

Minikin, A., D. Wagenbach, W. Grafand J. Kiplstuhl. 1994. Spatial and seasonal variations of the snow chemistry at the central Filchner-Ronne Ice Shelf, Antarctica. Ann. Glaciol., 20, 283-290.

Mulvancy, R., F.W. Wolff and K. Oates. 1988. Sulphuric acid at grain boundaries in Antarctic ice. Nature, 331 (6153), 247249

Mulvaney, R., E. C. Pasteur, D. A. Peel, E. S. Saltzman and P.-Y. Whung. 1992. The ratio of MSA to non-sca-salt sulphate in Antarctic Peninsula icc corss. 'Fellurs, 44B 4 ). 295-303.

Pasteur, E. C. 1996. Biogenic sulphur in Antarctic ice cores. (Ph.D. thesis University of East Anglia.)

Pasteur, E. C., R. Mulvaney, D. A. Peel, E. S. Saltzman and P.-Y. Whung. 1995. A 340 ycar record of biogenic sulphur from the Weddell Sea area, Antarctica. Ann. Glaciol., 21, 169-174.

Savoie, D. L. and 8 others. 1993. Nitrogen and sulphur species in Antarctic acrosols at Mawson, Palmer Station and Marsh (King George Island) 7. Atmos. Chem., 17(2), 95122.

Spiro, P. A., D. J. Jacobs and J. A. Logan. 1992. Global inventory of sulphur emissions with $1^{\circ} \times 1^{\circ}$ resolution. 7. Geophys. Res., 97(D5), 6023-6036.

Stephen, H. and T. Stephen, eds. 1963. Solubilaties of inorganic and organic compounds. Vol. 1. Oxford, Pergamon Press.

Wagenbach, D. 1996. Coastal Antarctica: atmospheric chemical composition and atmospheric transport. In Wolff, E.W. and R. C. Bales, eds Chemical exchange between the atmosphere and polar snose. Berlin, ctc., SpringrrVerlag, 173-199. (NATO ASI Series I: Global Environmental Change 43.) 